\title{
Revisional bariatric surgery after failed laparoscopic adjustable gastric banding - a single-center, long-term retrospective study
}

\author{
Piotr K. Kowalewski ${ }^{1}$, Robert Olszewski ${ }^{2}$, Andrzej P. Kwiatkowski ${ }^{1}$, Krzysztof Paśnik ${ }^{1}$ \\ ${ }^{1}$ Department of General, Oncological, Metabolic and Thoracic Surgery, Military Institute of Medicine, Warsaw, Poland \\ ${ }^{2}$ Department of Cardiology, Military Institute of Medicine, Warsaw, Poland
}

\begin{abstract}
Introduction: Laparoscopic adjustable gastric banding (LAGB) used to be one of the most popular bariatric procedures.

Aim: To present our institution's experience with LAGB, its complications, causes of failure and revisional bariatric procedures, in a long-term follow-up.

Material and methods: Records of patients who underwent pars flaccida LAGB from 2003 to 2006 were gathered. We selected data on patients with a history of additional bariatric procedures. Their initial demographic data, body mass index and causes of revision were gathered. We analyzed length of stay and early perioperative complications. Results: 60\% of patients $(n=57)$ who underwent LAGB in our institution between 2003 and 2006 had their band removed (out of 107, 11\% lost to follow-up). Median time to revisional surgery was 50 months. The main reasons for removal were: weight regain $(n=23 ; 40 \%)$, band slippage $(n=14 ; 25 \%)$, and pouch dilatation $(n=9 ; 16 \%)$. Thirty (53\%) patients required additional bariatric surgery, 10 (33\%) of which were simultaneous with band removal. The most popular procedures were: laparoscopic Roux-en-Y gastric bypass (LRYGB) $(n=15 ; 50 \%)$, open gastric bypass $(n=8 ; 27 \%)$, and laparoscopic sleeve gastrectomy (LSG) - $(n=3 ; 10 \%)$. Mean length of stay (LOS) was $5.4 \pm 2.0$. One (3\%) perioperative complication was reported.

Conclusions: The results show that $L A G B$ is not an effective bariatric procedure in long-term follow-up due to the high rate of complications causing band removal and the high rate of obesity recurrence. Revisional bariatric surgery after failed LAGB may be performed in a one-stage approach with band removal.
\end{abstract}

Key words: bariatric surgery, laparoscopic adjustable gastric banding, gastric band, revision, long-term outcomes.

\section{Introduction}

Obesity has been classified as a disease by the American Medical and American Heart Associations since 2013 [1]. According to the World Health Organization, it affects 600 million people $-13 \%$ of the world's population is struggling with obesity. This number has doubled since 1980 [2]. Obesity alone, even without co-morbidities, bears significant health risks. Large prospective studies identified higher all- cause mortality among patients with a body mass index (BMI) over $30 \mathrm{~kg} / \mathrm{m}^{2}$ [3]. Since body weight loss reduces morbidity [1], various methods of treating obesity have rapidly developed in recent years. Bariatric surgery is proven to be the most effective weight loss management $[4,5]$, gaining worldwide popularity. Laparoscopic adjustable gastric banding (LAGB) for many years was one of the most popular procedures, representing almost $43 \%$ of all the operations in 2008. Yet, after 2013, the number of 
LAGB performed dropped to $10 \%$ or less [6-8]. This decrease may be attributed to the development of other bariatric procedures such as laparoscopic sleeve gastrectomy (LSG), yet it may also be caused by LAGB's poor long-term outcomes and high rate of band complications. Bariatric surgeons frequently treat patients with failed adjustable gastric banding. We would like to present our institution's experience with LAGB, its complications, causes of failure and revisional bariatric procedures, in a long-term follow-up observation.

\section{Aim}

The aim of this study was to evaluate the rate and causes of failure of the adjustable gastric bands in a long-term follow-up along with an analysis of the additional bariatric procedures for patients with recurring obesity.

\section{Material and methods}

We revised our patients' data searching for bariatric procedures performed over 10 years ago. We identified patients who underwent LAGB via pars flaccida from 2003 to 2006 and selected the group who had their band removed. These patients were included in our study. We gathered their initial demographic data, weight, and BMI along with details regarding causes of band failure. Patients who underwent an additional bariatric procedure besides the removal of the band were also identified with their weight and $\mathrm{BMI}$, type of bariatric procedure and length of hospital stay after the surgery.

\section{Statistical analysis}

Statistical analysis was performed using Statistica software (StatSoft). Normality of the data was tested with the Shapiro-Wilk test.

\section{Results}

For the purpose of this study we analyzed the data on patients who underwent LAGB in the years 2003-2006. The median follow-up was 11.2 years (ranging from 10.4 to 12.5$)$. Twelve (11\%) patients were lost to follow-up, and there was one perioperative death $(0.9 \%)$ caused by septic shock which originated from an iatrogenic gastric leakage. We focused on the 57 patients (46 females and 11 males, 60\%) who had the band removed.
Their median BMI before the LAGB was $40.5 \mathrm{~kg} / \mathrm{m}^{2}$. The demographic data before the initial procedure are presented in Table I. The median time to second surgery was 50 months. Minimal time to band removal was 3 days due to pathological contraction of the band. The longest noted period between LAGB and the revisional procedure was 133 months. Several, often co-existing complications led to the band's removal, such as: weight gain (40\%), pouch slippage (25\%), infection and dislocation of the port (21\%), pouch dilatation (16\%), and band erosion (5\%) (Table II). Annual distribution of additional surgery is presented in Figure 1. Out of the studied group, 30 (53\%) patients underwent another bariatric procedure (Table III). Their BMI before the second surgery was $39.2 \pm 5.0 \mathrm{~kg} / \mathrm{m}^{2}$. Ten $(33 \%)$ of the procedures were simultaneous with the removal of the band. The most popular procedure was laparoscopic Roux-en-Y gastric bypass (LRYGB) - 15 (50\%). The others were: open gastric bypass (GB) - 8 (27\%), LSG - 3 (10\%), biliopancreatic division/duodenal switch (BPD/DS) 2 (7\%), open sleeve gastrectomy - 1 (3\%) and port reimplantation -1 (3\%). The type of procedure was independently chosen by the consultant based on existing guidelines (bearing in mind for example on the metabolic co-morbidities, dietary habits, etc.). The number of open bariatric revisional procedures dropped over the years. From 2012 every revisional surgery was performed laparoscopically (Figure 2). Mean length of stay (LOS) after the second bariatric surgery was $5.4 \pm 2.0$, ranging from two days after LSG to 11 days after open GB (Figure 3). In 2007 the LOS was 7.8 days and dropped to 3.25 days in 2014. We encountered one perioperative complication (3\%) - a hemorrhage from short gastric vessels during LRYGB which required a conversion to open surgery and performing an esophago-jejunal anastomosis, instead of a gastro-jejunal one.

Table I. Demographic data before laparoscopic adjustable gastric banding $(n=57)$

\begin{tabular}{|lcc|}
\hline Parameter & Value & $\begin{array}{c}\%(\mathrm{SD}) \\
\text { [range] }\end{array}$ \\
\hline Gender (female/male) & $46 / 11$ & $80 \% / 20 \%$ \\
\hline Mean age & 34.1 & {$[16-52]$} \\
\hline Median body mass index $\left[\mathrm{kg} / \mathrm{m}^{2}\right]$ & 40.5 & {$[29-56.8]$} \\
\hline Mean weight $[\mathrm{kg}]$ & 116.0 & \pm 20.4 \\
\hline
\end{tabular}


Table II. Causes of revisional surgery after laparoscopic adjustable gastric banding $(n=57)$

\begin{tabular}{|lcc|}
\hline Causes & $N$ & $\%$ \\
\hline Port problem (infection, dislocation) & 12 & 21 \\
\hline Slippage & 14 & 25 \\
\hline Pouch dilatation and reflux & 9 & 16 \\
\hline Band erosion & 3 & 5 \\
\hline Co-existing or independent weight gain & 23 & 40 \\
\hline
\end{tabular}

Table III. Types of revisional bariatric procedures after band removal $(n=30)$

\begin{tabular}{|lccc|}
\hline Procedure & N & $\%$ & Simultaneous \\
\hline Gastric bypass (GB): & 23 & 77 & 9 \\
\hline Laparoscopic GB & 15 & 50 & 4 \\
\hline Open GB & 8 & 27 & 5 \\
\hline Sleeve gastrectomy (SG): & 4 & 13 & 1 \\
\hline Laparoscopic SG & 3 & 10 & 1 \\
\hline Open SG & 1 & 3 & 0 \\
\hline $\begin{array}{l}\text { Biliopancreatic diversion/ } \\
\text { duodenal switch (BPD/DS) }\end{array}$ & 2 & 7 & 0 \\
\hline Re-implantation of the port & 1 & 3 & 0 \\
\hline
\end{tabular}

\section{Discussion}

Laparoscopic adjustable gastric banding is a fairly uncomplicated, fast, minimally invasive and reversible procedure. All of those qualities made it one of the most popular operations among bariatric surgeons and patients. Even in 2013 almost 40000

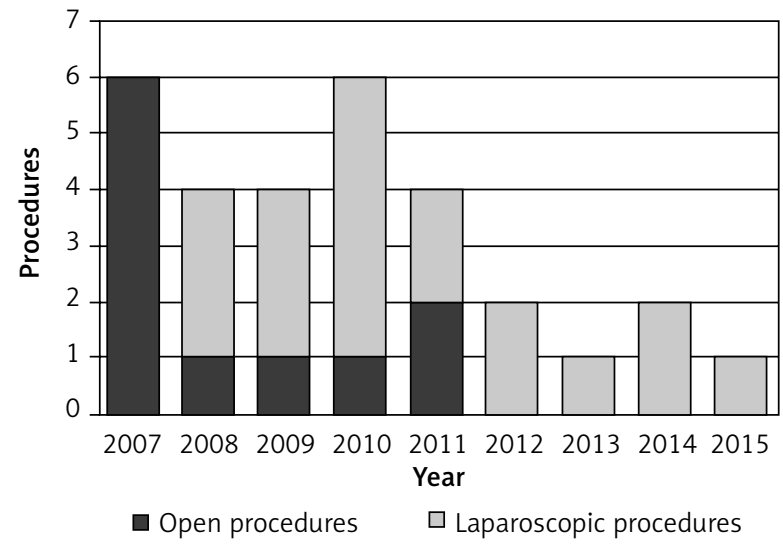

Figure 2. Laparoscopic vs. open additional bariatric procedures after failed laparoscopic adjustable gastric banding per year

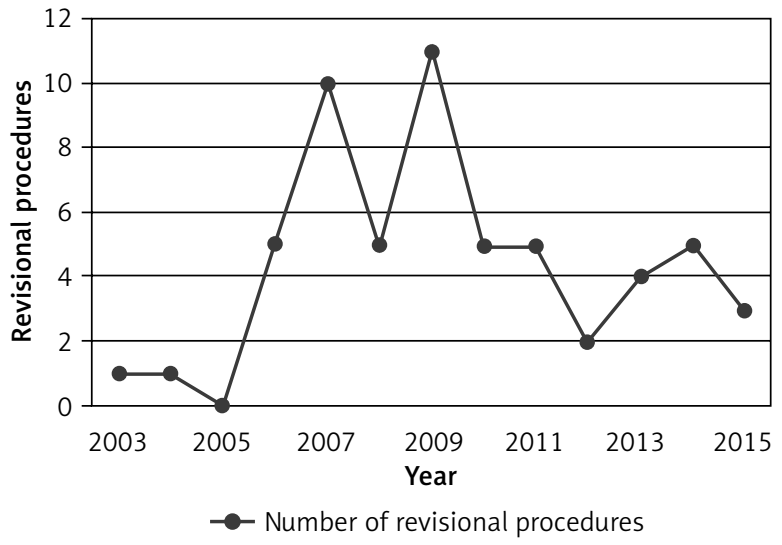

Figure 1. Number of bariatric procedures after laparoscopic adjustable gastric banding per year

patients underwent this operation worldwide [1]. Promising short- and medium-term results do not continue in long-term studies. Although some authors report a stunning $47 \%$ excess weight loss (\%EWL) in a 15-year follow-up [9], in other publications the successful effect of LAGB is maintained in the long-term in $12 \%$ to $40 \%$ of the patients [10-12]. Unsatisfactory \%EWL is not the only disadvantage of LAGB. Almost every long-term study focuses on the high rate of revisional procedures. Altieri et al. reported a $20.22 \%$ revision or removal rate after a seven-year analysis of almost 20000 cases of LAGB [13]. A large study of 53000 cases by Lazzati et al. revealed an even higher removal rate of $40 \%$ [14]. Smaller studies report up to $78.5 \%$ of all LAGB being surgically revised, with $72.7 \%$ of the bands being removed [15]. The main complications leading

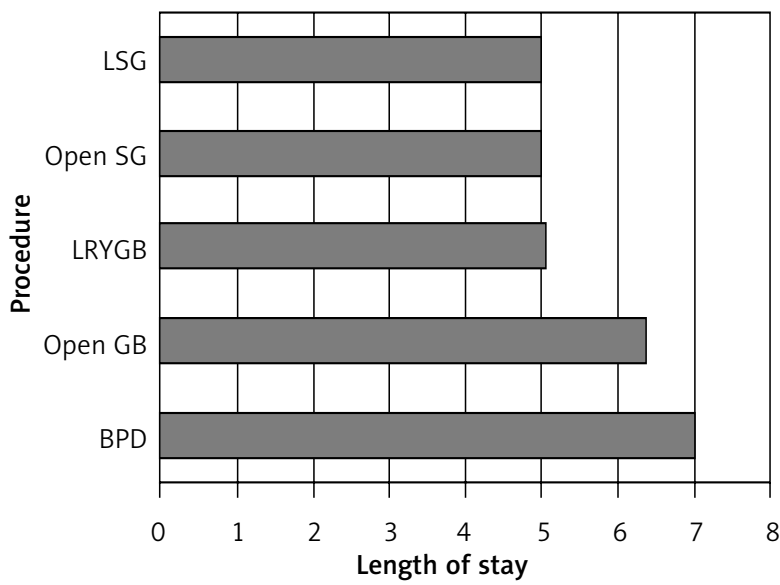

Figure 3. Length of stay depending on type of additional bariatric procedure 
to band removal are pouch enlargement (14-18.3\%) and slippage (8-13.3\%) [10, 16-19], which is similar to our results. Weight regain, whether with an active gastric band or after its removal, is another major issue regarding long-term effects of LAGB. Our study shows that it affected $40 \%$ of patients before band removal, yet $53 \%$ of all patients included in this study underwent another bariatric procedure, due to weight regain after removal of the band. The remaining $47 \%$ are either still qualifying for an additional procedure or decided to waive bariatric surgery and therefore did not complete additional follow-up. A similar rate of recurrence of obesity (29-75\%) is reported by other authors [10, 20,21]. While approaching revisional bariatric surgery after failed LAGB, LSG and LRYGB are safe procedures [21, 22]. The one-stage surgical approach seems to be as safe as two-stage, yet there are only a few studies evaluating these approaches [23]. The LOS after revisional surgery is longer than standard LOS after primary bariatric surgery (4.18 days), but over the years, following the learning curve, it was possible to reduce LOS to 3.25 days in 2014 [24].

Our study is one of a few that analyzes only the pars flaccida LAGB, not including the previous perigastric techniques. It is also one of the few with a lost-to-follow-up rate of $11.2 \%$, while large observational studies report up to $83 \%$ of cases being lost to follow-up [13].

\section{Conclusions}

Sixty percent of all LAGB patients suffered a complication which required band removal. Over half of those patients (53\%) required another bariatric procedure due to recurrent obesity. Bearing in mind these results, LAGB should not be considered a longterm effective bariatric procedure. Additional bariatric operations after LAGB may be performed laparoscopically by an experienced surgeon. Length of stay is longer than with the initial bariatric surgery.

\section{Conflict of interest}

The authors declare no conflict of interest.

\section{References}

1. Jensen MD, Ryan DH, Apovian CM, et al. 2013 AHA/ACC/TOS guideline for the management of overweight and obesity in adults: a report of the American College of Cardiology/American Heart Association task force on practice guidelines and the obesity society. Circulation 2014; 129: 102-41.
2. World Health Organization. Obesity and overweight - January 2015.

3. Flegal KM, Kit BK, Orpana H, et al. Association of all-cause mortality with overweight and obesity using standard body mass index categories: a systematic review and meta-analysis. JAMA 2013; 309: 71-82.

4. Colquitt JL, Pickett K, Loveman E, et al. Surgery for weight loss in adults. Cochrane Database Syst Rev 2014; 8: CD003641.

5. Gloy VL, Briel M, Bhatt DL, et al. Bariatric surgery versus nonsurgical treatment for obesity: a systematic review and meta-analysis of randomised controlled trials. BMJ 2013; 347: f5934.

6. Buchwald H, Oien DM. Metabolic/bariatric surgery worldwide 2008. Obes Surg 2009; 19: 1605-11.

7. Angrisani L, Santonicola A, lovino P, et al. Bariatric surgery worldwide 2013. Obes Surg 2015; 25: 1822-32.

8. Janik MR, Stanowski E, Paśnik K. Present status of bariatric surgery in Poland. Videosurgery Miniinv 2016; 11: 22-5.

9. O'Brien PE, MacDonald L, Anderson M, et al. Long-term outcomes after bariatric surgery: fifteen-year follow-up of adjustable gastric banding and a systematic review of the bariatric surgical literature. Ann Surg 2013; 257: 87-94.

10. Aarts EO, Dogan K, Koehestanie P, et al. Long-term results after laparoscopic adjustable gastric banding: a mean fourteen year follow-up study. Surg Obes Relat Dis 2014; 10: 633-40.

11. Suter M, Calmes JM, Paroz A, et al. A 10-year experience with laparoscopic gastric banding for morbid obesity: high longterm complication and failure rates. Obes Surg 2006; 16: 829-35.

12. Kowalewski PK, Olszewski R, Kwiatkowski A, et al. Life with a gastric band. Long-term outcomes of laparoscopic adjustable gastric banding - a retrospective study. Obes Surg 2016; in press.

13. Altieri MS, Yang J, Telem DA, et al. Lap band outcomes from 19,221 patients across centers and over a decade within the state of New York. Surg Endosc 2016; 30: 1725-32.

14. Lazzati A, De Antonio M, Paolino L, et al. Natural history of adjustable gastric banding: lifespan and revisional rate: a nationwide study on administrative data on 53,000 patients. Ann Surg 2017; 265: 439-45.

15. Toolabi K, Golzarand M, Farid R. Laparoscopic adjustable gastric banding: efficacy and consequences over a 13-year period. Am J Surg 2016; 212: 62-8.

16. Owers C, Ackroyd R. A study examining the complications associated with gastric banding. Obes Surg 2013; 23: 56-9.

17. Victorzon M, Tolonen P. Mean fourteen-year, $100 \%$ follow-up of laparoscopic adjustable gastric banding for morbid obesity. Surg Obes Relat Dis 2013; 9: 753-7.

18. Razak Hady H, Dadan J, Sołdatow M, et al. Complications after laparoscopic gastric banding in own material. Videosurgery Miniinv 2012; 7: 166-74.

19. Szydłowski K, Orłowski M, Frask A, et al. Complications after surgical treatment of obesity based on own material. Videosurgery Miniinv 2008; 3: 45-52.

20. Brown JJS, Boyle M, Mahawar K, et al. Laparoscopic adjustable gastric band survival in a high-volume bariatric unit. Br J Surg 2013; 100: 1614-8 
21. Marin-Perez P, Betancourt A, Lamota M, et al. Outcomes after laparoscopic conversion of failed adjustable gastric banding to sleeve gastrectomy or Roux-en-Y gastric bypass. Br J Surg 2014; 101: 254-60.

22. Alqahtani AR, Elahmedi MO, Al Qahtani AR, et al. 5-year outcomes of 1-stage gastric band removal and sleeve gastrectomy. Surg Obes Relat Dis 2016; 12: 1769-76.

23. Lewis CS, Varma AK, Hamdorf JM. Comparison of safety between 1-stage and 2-stage surgery: from laparoscopic adjustable gastric banding to laparoscopic sleeve gastrectomy. Surg Obes Relat Dis 2015; 12: 976-83.

24. Simonelli V, Goergen M, Orlando GG, et al. Fast-track in bariatric and metabolic surgery: feasibility and cost analysis through a matched-cohort study in a single centre. Obes Surg 2016; 26: 1970-7.

Received: 24.11.2016, accepted: 26.02.2017. 